\title{
Correction: Adding Vitamin E-TPGS to the Formulation of Genexol-PM: Specially Mixed Micelles Improve Drug-Loading Ability and Cytotoxicity against Multidrug-Resistant Tumors Significantly
}

The PLOS ONE Staff

In the PDF, Figs 6 and 7 incorrectly appear as duplicates of Figs 10 and 11. The HTML version and figure legends are correct. The publisher apologizes for the error. Please see the correct versions of Figs 6 and 7 here.

f open access

Citation: The PLOS ONE Staff (2015) Correction: Adding Vitamin E-TPGS to the Formulation of Genexol-PM: Specially Mixed Micelles Improve DrugLoading Ability and Cytotoxicity against MultidrugResistant Tumors Significantly. PLOS ONE 10(5): e0127343. doi:10.1371/journal.pone.0127343

Published: May 7, 2015

Copyright: $\odot 2015$ The PLOS ONE Staff. This is an open access article distributed under the terms of the Creative Commons Attribution License, which permits unrestricted use, distribution, and reproduction in any medium, provided the original author and source are credited. 


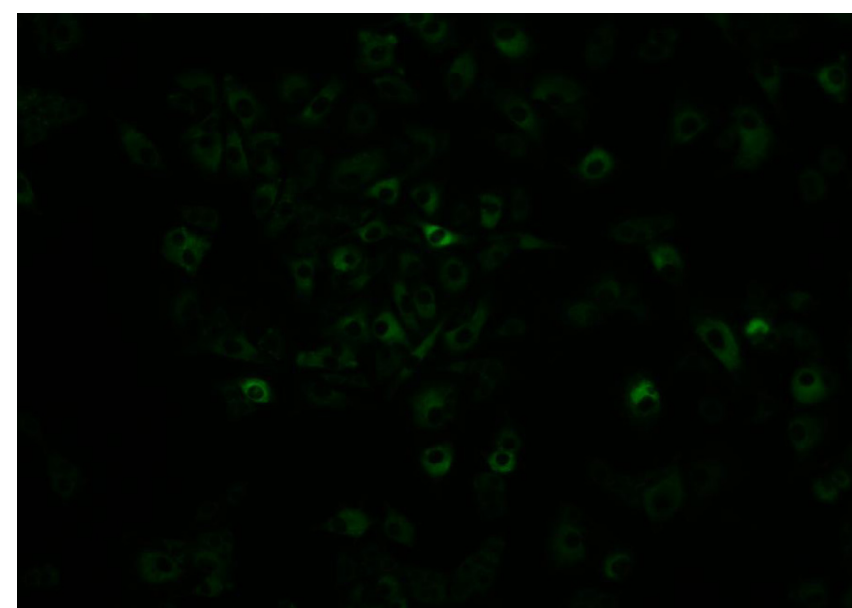

A

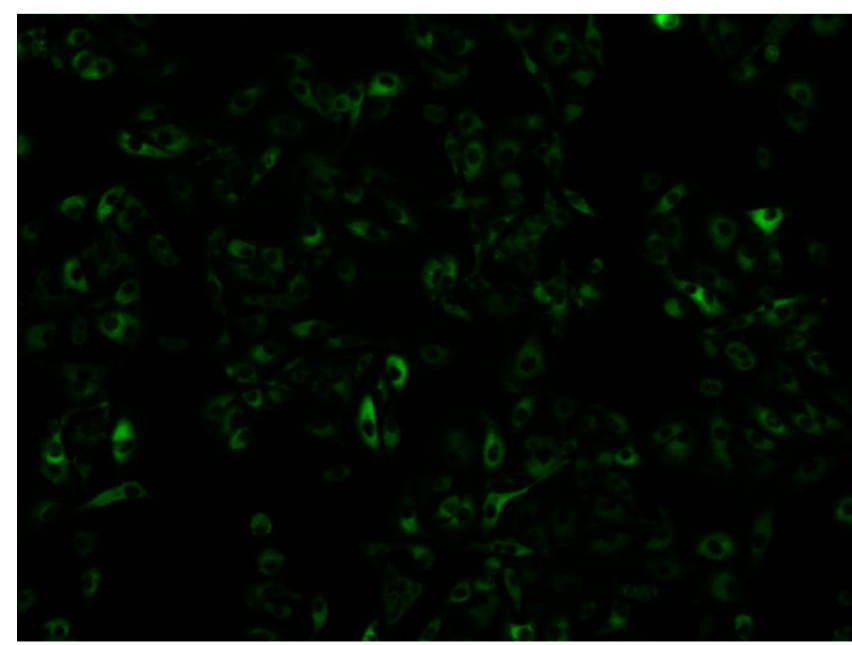

C

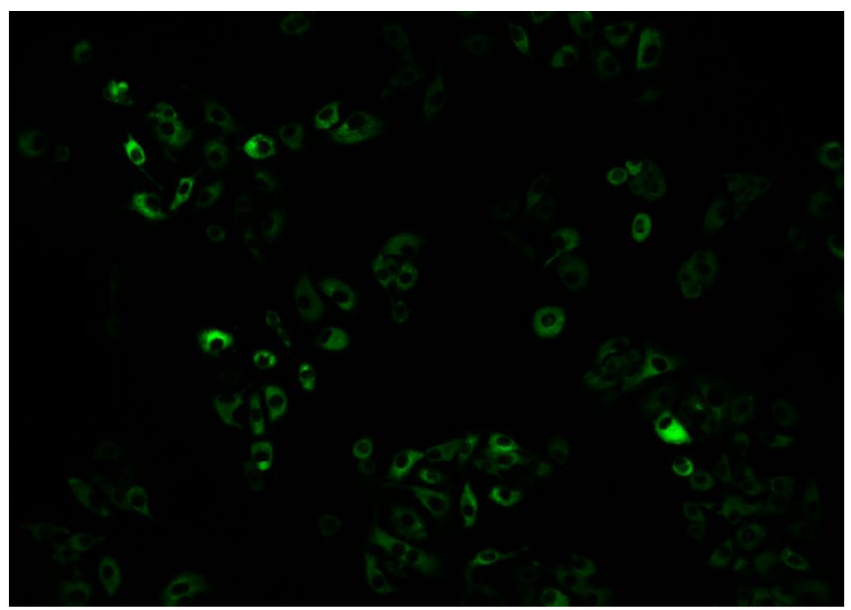

B

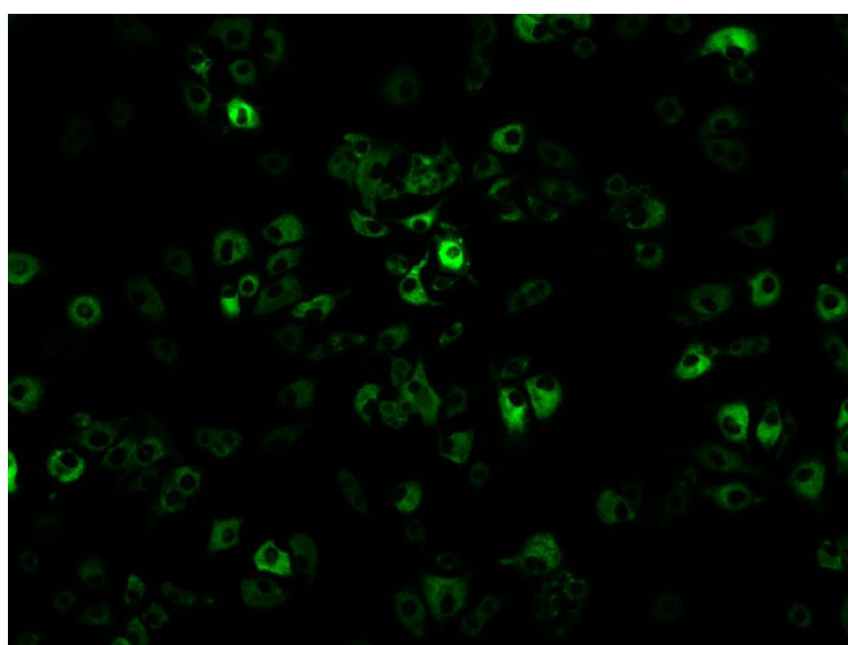

D

Fig 6. A549 cell uptake (A) after $15 \mathrm{~min}$ and (B) after $1 \mathrm{~h}$ of culture with coumarin-6-loaded (a fluorescence probe, green) PEG-PLA micelles and (C) after $15 \mathrm{~min}$ and $(\mathrm{D})$ after $1 \mathrm{~h}$ of culture with coumarin-6-loaded mixed micelles.

doi:10.1371/journal.pone.0127343.g001 


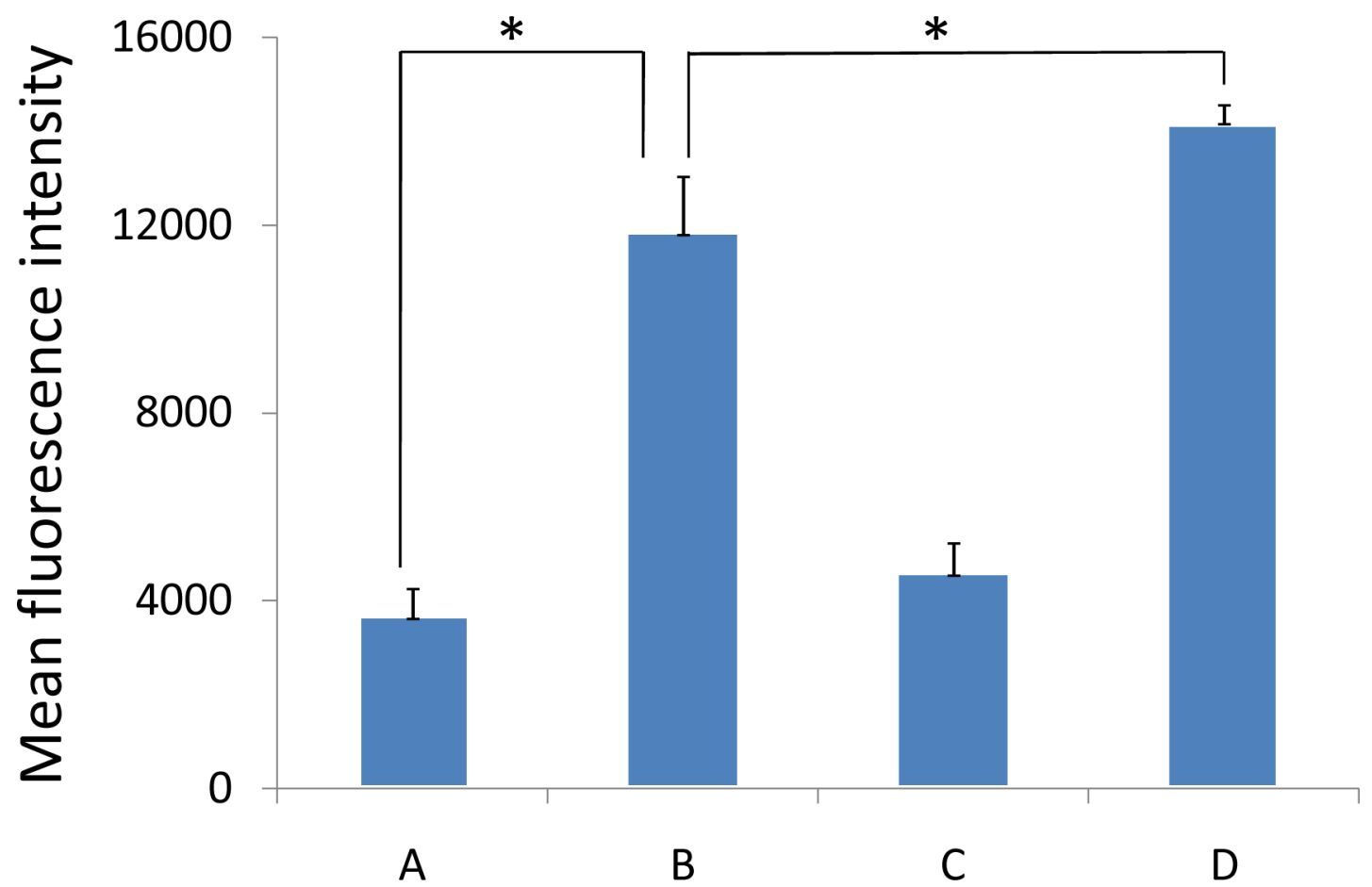

Fig 7. Quantitation of mean fluorescence intensity of coumarin 6 in A549 cells (A) after 15 min and (B) after $1 \mathrm{~h}$ of culture with coumarin-6-loaded PEG-PLA micelles and (C) after $15 \mathrm{~min}$ and (D) after $1 \mathrm{~h}$ of culture with coumarin-6-loaded mixed micelles.

doi:10.1371/journal.pone.0127343.g002

\section{Reference}

1. Fan Z, Chen C, Pang X, Yu Z, Qi Y, Chen X, et al. (2015) Adding Vitamin E-TPGS to the Formulation of Genexol-PM: Specially Mixed Micelles Improve Drug-Loading Ability and Cytotoxicity against Multidrug-Resistant Tumors Significantly. PLoS ONE 10(4): e0120129. doi: 10.1371/journal.pone.0120129 PMID: 25831130 